\title{
Studieleiders coachen het zelfsturend leren: Nijmeegse ervaring
}

\author{
R.P. Bos, G.A.M. Ophelders
}

\section{Samenvatting}

In de nieuwe bachelor-master (BaMa) structuur van de opleiding biomedische wetenschappen $(B M W)$ van de Radboud Universiteit Nijmegen is voor de student in de keuzefase (master) het aantal keuzemomenten flink toegenomen. Om de studenten in dit keuzeproces te begeleiden zijn zes studieleiders aangesteld. Dit artikel beschrijft de taken en verantwoordelijkheden van deze studieleiders in de nieuwe onderwijskundige en organisatorische omgeving. De meerwaarde van het instituut 'studieleider' wordt gevalideerd en gespiegeld aan literatuur over zelfsturing, zelfreflectie en de zelfverantwoordelijkheid voor leren van studenten. Daarnaast wordt uitgebreid ingegaan op de gewenste eigenschappen van de studieleider. Het effect van hun werk wordt onderzocht met behulp van semi-gestructureerde interviews met individuele studieleiders en een groepsinterview. Aanvullende informatie werd verkregen uit het rapport van de Visitatiecommissie Biomedische Wetenschappen en Medische Informatiekunde (2004). Als conclusie kan worden gesteld dat studieleiders effectief zijn en dat zij een goede balans hebben gevonden tussen de begeleiding en zelfsturing van studenten. (Bos RP, Ophelders GAM. Studieleiders coachen het zelfsturend leren: Nijmeegse ervaring. Tijdschrift voor Medisch Onderwijs 2006;25(5):208-217.)

\section{Inleiding}

Uit een door Schol et al. uitgevoerde evaluatie blijkt de begeleiding van studenten die persoonlijke leerplannen hebben gemaakt effectiever te zijn dan de gebruikelijke onderwijsvormen. ${ }^{1}$ Het maken van deze leerplannen houdt in dat studenten actiever worden in het sturen van hun eigen leren.

Over het begrip 'zelfsturing' is het laatste decennium veel geschreven. Individuen die zichzelf kunnen sturen zouden hun weg in een informatiemaatschappij annex kenniseconomie gemakkelijker kunnen vinden en goed voorbereid zijn om de snelle veranderingen in bedrijf en beroep aan te kunnen. ${ }^{2-3}$

Is de meeste literatuur nog vooral beschrijvend van aard, de laatste jaren verschijnen er steeds meer empirische studies over het onderwerp. In een recent artikel van Grevenson en Spencer ${ }^{4}$ wor- den een groot aantal onderzoeken kort beschreven, die alle kanttekeningen plaatsen bij zelfgestuurd leren ('self-directed learning' in het Engels). De geschiktheid van studenten voor zelfsturend leren wordt niet altijd even solide bevonden.

We zullen een aantal punten uit de literatuur over zelfsturing bespreken die met name gerelateerd zijn aan de begeleiding door de docent. We beschrijven vooral de conclusies en gaan alleen in op onderzoeksmethodieken en de setting van de studenten als dat voor de duidelijkheid nodig is.

Dornan et al. 5 concluderen dat derdejaars studenten zich zelden volledig autonoom gedragen; ze stellen ondersteuning en sturing op organisatorisch, affectief en pedagogisch gebied op prijs. Op organisatorisch gebied kunnen we dan denken aan het creëren van leermogelijkheden. Hieronder worden omstandighe- 
den verstaan die zich voordoen in de leeromgeving om de student de juiste leeractiviteiten uit te laten voeren. Pedagogisch houdt dat in dat de docent doelen en methoden aanraadt of feedback geeft. Op affectief gebied gaat het om het stellen van eisen, het geven van toestemming en het helpen van studenten bij hun groei naar een meer onafhankelijke leerstijl. Deze vormen van ondersteuning motiveren studenten meer dan wanneer er alleen inhoud wordt overgedragen. Tevens zijn ze beter in staat hun leerbehoeften te identificeren.

Eva $^{6}$ ondersteunt deze conclusie als hij stelt dat (medisch) studenten altijd externe sturing nodig hebben wanneer ze geconfronteerd worden met onbekende praktijkgebieden. "Appropriately supported, medical students are very active learners." 5 Ook in het proefschrift van Taks ${ }^{7}$ vinden we hier bewijs voor. Haar onderzoek was gericht op het geven van een beschrijving van de belemmeringen en mogelijkheden die zich voordoen bij het vormgeven van zelfsturing in de onderwijspraktijk. Twee opvallende conclusies uit haar onderzoek nemen we hier op. Ten eerste verwachten docenten vaak een te hoge mate van zelfsturing van studenten. Studenten worden daarom onvoldoende ondersteund, vooral op het gebied van leren leren. Witteman ${ }^{8}$ constateert dat studenten metacognitieve vaardigheden (vaardigheden die het leerproces sturen, zoals plannen, oriënteren, evalueren, reflecteren) eerder impliciet aanleren: het zijn eigenlijk nevenproducten van de leerprocessen. Een tweede conclusie uit het onderzoek van Taks is dat ondersteuning van zelfsturing tijdsintensief is. Met name in het begin van de opleiding en van een nieuwe module of onderwijseenheid blijkt veel ondersteuning nodig te zijn.

Er zijn meer auteurs die pleiten voor een geleidelijke opbouw van het leerpro- ces. Stijnen en Dieleman, bijvoorbeeld, vragen zich af: "Kunnen studenten hun eigen beperkte kennis gebruiken als middel om toegang tot iets te krijgen dat ze nog niet begrijpen?"9 Ook blijken (zeker eerstejaars) studenten moeilijk tot leervragen te komen en nog weinig vaardig te zijn in het reflecteren: twee vaardigheden die in het 'nieuwe leren' wat zelfsturing betreft een wezenlijke plaats innemen. "Zolang lerenden niet in staat zijn op efficiënte wijze hun eigen leerproces te reguleren (...) blijft begeleiding (...) een cruciale factor bij het werken met open leeromgevingen."10

Wat de individuele student betreft, is het van belang te vermelden dat het idee dat zelfsturing een relatief stabiel persoonlijkheidskenmerk is, niet valt vol te houden. Steeds meer auteurs ${ }^{3-4}$ beweren dat de mogelijkheid en de motivatie om zichzelf te sturen niet alleen afhangt van de leercontext, maar ook van het te bestuderen onderwerp, de sociale, culturele en onderwijskundige setting, eerdere ervaringen, het zelfbeeld en van reeds opgedane studievaardigheden. Vermetten ${ }^{11}$ constateerde in haar promotieonderzoek dat de manier van leren van studenten redelijk stabiel is over de tijd en over verschillende cursussen heen, maar zeker ook niet onveranderlijk. De algemene conclusie is dat er een nieuwe oriëntatie op zelfgestuurd leren dient plaats te vinden, waarin eenvoudige opvattingen over zelfsturing worden opgenomen. ${ }^{12-13}$

\section{De onderwijskundige vernieuwing van biomedische wetenschappen}

In het curriculum biomedische wetenschappen te Nijmegen vormen zelfsturing en zelfverantwoordelijkheid voor het leren een essentieel aandachtspunt. De start hiermee is gemaakt in de bachelorfase; in de masterfase wordt dit principe nog versterkt aangezet. Om zelfsturend 
leren te begeleiden, zijn zes studieleiders benoemd die de studenten individueel coachen. Dit artikel spitst zich toe op de rol en de betekenis van de begeleiding door de studieleider.

Op basis van constructivistisch onderwijs is er een eigen, bij de Nijmeegse situatie passend, model van studentgericht onderwijs ${ }^{14-15}$ ontwikkeld. In dit model staat het functioneren van de toekomstige onderzoeker (in het werkveld) als inhoudelijk uitgangspunt van het curriculum centraal. De opleiding bestaat niet meer uit een stapeling van verschillende vakken met soms weinig onderlinge samenhang. De curriculuminhoud wordt vanaf het begin bepaald door een integratieve praktijkbril met als leidende vraag: Wat doet de onderzoeker in het werkveld (waarvan ook de universiteit deel uitmaakt)? Tevens worden analoog aan de praktijk, waarin mensen 'doen', de doelen geformuleerd in vaardigheden. Aan het einde van een opdracht reflecteren de studenten op het doel via het gemaakte product en de gevolgde aanpak (het proces). Als laatste levert de oriëntatie op het werkveld zinvolle situaties en een context voor het leren.

Een tweede kenmerk van de vernieuwde opleiding is de fundering van het onderwijs op het constructivisme. ${ }^{16-17}$ Ingevoerde leerprincipes zijn:

1. Studenten krijgen een zo actief mogelijke rol in de studie. In het opleidingsprogramma bestaat daarom $70 \%$ van de beschikbare studietijd uit zelfstudie, aangestuurd door zelfstudieopdrachten.

2. Het cumulatieve aspect: hetgeen later is geleerd bouwt op eerder verworven kennis en inzicht voort.

3. De aandacht voor reflectie. Reflecteren en feedback krijgen en geven, wordt al vroeg in de opleiding ingebouwd.

In de masterfase wordt onderwijskundig voortgebouwd op het studentgericht on- derwijsconcept door de student meer vrijheid te geven. De inrichting van de verschillende blokken loopt hiermee parallel: de zelfstudieopdrachten hebben een grotere tijdsomvang en bepaalde vaardigheden worden nu bekend verondersteld en komen niet specifiek terug in de opdrachten.

Een derde kenmerk heeft betrekking op de veranderende rol van de docent. Behalve informatieverstrekking krijgen leerprocesbegeleiding en het ontwikkelen van materiaal veel aandacht. Tevens opereert een docent meer in groepen dan voor de onderwijsvernieuwing. Zo wordt leermateriaal in teams samengesteld om van het begin af aan de afstemming en integratie van de verschillende onderdelen mee te kunnen nemen. Ook komen docenten, voordat een onderdeel gegeven gaat worden, bij elkaar om de gang van zaken door te spreken. Soms worden bepaalde colleges in duo's verzorgd.

Door de wijzigingen in de bachelorfase hebben de studieleiders ervaring opgedaan met de nieuwe docentrollen, maar in de masterfase gaan ze nog een stap verder. Ze geven de studenten meer vrijheid, zodat deze optimaal van hun andere instelling kunnen profiteren. Informatieverstrekker, leerprocesbegeleider en ontwikkelaar zijn de studieleiders al, maar nu verschuift hun rol meer naar voorlichter, organisator, coach en kwaliteitsbewaker. Zie hier de argumenten voor de introductie van de studieleider. De vraag is uiteraard of het concept 'studieleider' voldoet aan zijn uitgangspunt: de coaching van studenten?

\section{Methode}

\section{Onderwijsinterventie}

De eerste zes studieleiders zijn benoemd op grond van hun inhoudelijke kennis en contacten met het werkveld. Waar de stu- 
dieadviseur vooral in de bachelorfase een belangrijke rol had, wordt deze in de masterfase vooral vervuld door de studieleider. De studieleider begeleidt de studenten van het hoofdvak dat zij gekozen hebben. Het aantal studenten dat hij per jaargroep begeleidt, kan variëren van een tot meer dan twintig. De begeleiding houdt een aantal zaken in zoals hieronder besproken:

1. De studieleider heeft de eindverantwoordelijkheid voor de informatie en voorlichting die wordt gegeven over zijn hoofdvak.

2. De studieleider bespreekt de invulling van hun keuzeprogramma (hoofdvakstage, bijvakken en andere keuzeonderdelen) met de studenten die zijn hoofdvak hebben gekozen. Hij dient bij het samenstellen van het masterprogramma als baken, hij bewaakt de coherentie van het programma en hij kan door de Examencommissie worden aangesproken op het programma waar hij uiteindelijk mee heeft ingestemd.

3. De studieleider is verantwoordelijk voor de aansturing van de studenten met betrekking tot de werving, het contract en de beschrijving van de wetenschappelijke stage.

4. De studieleider is eindverantwoordelijk voor de beoordeling van de hoofdvakstage. De studenten moeten het verloop van hun eigen (master)programma bewaken. Van iedere student die zijn hoofdvak doet, wordt door de studieleider een archief bijgehouden van de correspondentie, de verslagen van de besprekingen, stageverslagen en andere relevante documenten. Bij problemen (bijvoorbeeld ernstige vertraging) neemt hij contact op met de student of de docent/begeleider van het betreffende onderdeel.

5. De studieleider is qualitate qua voorzitter van de betreffende hoofdvakcom- missie en lid van de keuzefasecommissie. De hoofdvakcommissie is in feite de denktank van het hoofdvak. Hierin hebben o.a. externe adviseurs en personen die door hun functie zicht hebben op de benodigde kwaliteiten van door ons opgeleide BMW'ers zitting.

6. De zes studieleiders zijn verenigd in een commissie met een onafhankelijke voorzitter die regelmatig bijeenkomt en waarbinnen zaken die samenhangen met het keuzecurriculum en de hoofdvakken worden besproken en onderling afgestemd. De studieleiders bespreken onder andere de resultaten van een evaluatiesysteem, waarin alle onderdelen van het curriculum jaarlijks kritisch onder de loep worden genomen.

\section{Instrumenten}

Gezien het kleine aantal respondenten zijn twee manieren gebruikt om data te verzamelen aangaande het functioneren van de studieleiders in de masterfase van de opleiding biomedische wetenschappen. Daarnaast is een onafhankelijk rapport gebruikt. Op deze wijze kunnen wij vanuit meerdere gezichtspunten en met behulp van verschillende methoden tot een oordeel komen over het instituut studieleider. Door deze vorm van triangulatie ${ }^{18}$ hebben we een vrij compleet en valide beeld van de werkwijze en het effect van de studieleiders op de studenten kunnen krijgen.

\section{Respondenten}

Er zijn zes studieleiders, die zowel aan het interview als aan de groepsdiscussie hebben deelgenomen. Daarnaast heeft de commissie tijdens de onderwijsvisitatie van 2004 de studenten expliciet bevraagd over de inzet van de studieleiders in de masterfase. Het ging hier om een tiental studenten. 


\section{Interview}

Het interview dat door de IOWO-auteur is afgenomen bij de studieleiders, was voornamelijk gericht op het onderzoeken van hun visie op de zelfverantwoordelijkheid van en de zelfsturing door studenten bij hun leren en de rol van de studieleider daarin. De interviews waren semi-gestructureerd. Een zevental vragen (tabel 1) lagen vast en op basis van de antwoorden werd doorgevraagd, met name over het bevorderen van de zelfsturing en wat de studieleiders daar voor nodig hebben. Alle studieleiders zijn door de auteurs per mail uitgenodigd deel te nemen aan de interviews. De individuele interviews duurden ongeveer 45 minuten. Van de individuele verslagen is een algemene notitie opge- steld, die als uitgangspunt is gebruikt voor de opstelling van vragen voor de groepsdiscussie.

\section{Groepsdiscussie}

Voor de groepsdiscussie is gebruikt gemaakt van de vorm 'focusgroep'. ${ }^{19}$ Op basis van de antwoorden uit de individuele interviews is een aantal vragen geformuleerd voor het groepsinterview (tabel 2). Het interview duurde twee uren. Naast de zes studieleiders werd deelgenomen door de beleidsmedewerkers biomedische wetenschappen en een lid van het Onderwijs Management Team (OMT). De IOWO-adviseur heeft de bijeenkomst geleid en het interview afgenomen.

Tabel 1. Vragen interview studieleiders.

1. Het nieuwe onderwijsconcept legt de verantwoordelijkheid voor het leren bij de student.

- Wat is - als studieleider - jullie kijk op dit doel van het concept?

- Wat doen jullie om die verantwoordelijkheid daar te laten en/of te stimuleren?

2. Jullie hebben een groot aantal taken.

- Welke twee taken vinden jullie essentieel?

- Hoe vullen jullie die twee taken concreet in?

3. Wat motiveert jullie om studieleider te zijn?

4. Wat hebben jullie nodig om jullie taken goed te kunnen uitvoeren? (Denk aan: de directe omgeving, je eigen professionaliteit, de leidinggevende/organisatie, de interactie tussen actoren en dergelijke).

5. Hoe gaan jullie om met de studieplanning van de student (student steeds vrijer laten, alles regelen, andere combinaties)?

6. Wat is voor jullie de winst van het systeem van studieleiders voor de student?

7. Wat willen jullie nog kwijt, waarvan jullie denken dat van belang is voor het schrijven van het artikel?

Tabel 2. Vragen groepsinterview studieleiders.

1. Hoe kunnen jullie de zelfsturing en zelfverantwoordelijkheid voor het leren van de studenten vergroten?

2. Hoe kijken jullie dan tegen het huidige takenpakket aan?

3. Wat betekent (het antwoord op vraag 1) specifiek voor jullie coachende vaardigheden op dit moment?

4. Stel jullie zouden een nieuwe collega moeten aantrekken. Aan welke eisen zou die moeten voldoen?

5. Welke ontwikkelingen in de nabije toekomst kunnen van invloed zijn op het concept 'studieleider'? Wat betekent dat voor de rol die hij nu heeft en voor de eigenschappen waarover hij nu dient te beschikken?

6. Wat maakt het concept geslaagd?

7. Wat betekent dat voor de infrastructuur rondom de studieleider?

8. Na een vijfjarig bestaan terugkijken: Wat levert het systeem op in relatie tot wat het kost? 
De visitatie door Qanu

De door Qanu gevolgde werkwijze is het VSNU-protocol Onderwijsvisitatie op maat.

\section{Resultaten}

\section{Wat vinden de studieleiders?}

Uit de individuele interviews blijkt dat enkele studieleiders het informeren van de studenten en het bewaken van hun studieprogrammering de belangrijkste taken vinden. Anderen leggen meer het accent op procesbegeleiding, waarin het stimuleren van zelfsturing en zelfreflectie een belangrijke plaats inneemt. Daarnaast wordt gecoacht, wat voornamelijk inhoud krijgt door het stellen van open vragen. Het voordeel van deze aanpak is dat vrij nauwkeurig bij de persoonlijkheid van de student kan worden aangesloten.

Op de vraag wat de studieleider motiveert, blijkt dat de studieleiders zich in hun werk vooral laten leiden door de betrokkenheid bij de student, de jongere die zich ontwikkelt.

De studieleiders vinden allen dat de studenten zelf verantwoordelijk zijn voor hun leerproces/studieprogramma. Zij worden dan ook in dat opzicht erg vrij gelaten. Om aan die verantwoordelijkheid te werken laat men de studenten zelf veel uitzoeken en doen.

Dat een student toch af en toe tegen zijn grenzen aanloopt en de studieleider onder bepaalde omstandigheden tot actie moet overgaan, is uitzondering. Dit kan bijvoorbeeld het geval zijn wanneer een stage niet voldoet aan de verwachtingen. Mocht een student er na discussie met de stageverlenende afdeling zelf niet uitkomen, ook niet na advies van de studieleider, dan moet deze laatste zelf tot actie overgaan. De studieleider leert op zijn beurt van de ervaringen die hij in dit proces opdoet.
Om hun taak goed te kunnen uitoefenen, vinden de studieleiders dat ze goed ingebed dienen te zijn in de afdeling, een breed nationaal en internationaal netwerk moeten hebben (i.v.m. stages) en actief en deskundig dienen te zijn op hun vakgebied. Tevens dient er op de faculteit sprake te zijn van een goed werkende infrastructuur.

Tijdens de groepsdiscussie kwamen een aantal belangrijke eigenschappen/ wenselijkheden ten aanzien van een functieomschrijving van de studieleider naar voren, zoals:

- Een open, communicatieve persoonlijkheid.

- Betrokkenheid bij en visie op het onderwijs en de onderzoeksmogelijkheden van biomedische wetenschappen en het betreffende hoofdvak .

- Het kiezen voor het belang van de student boven een ander belang, zoals dat van de afdeling.

- Een stimulerend, motiverend, coachend en triggerend optreden.

- In staat zijn om zelfstandig wegen te vinden.

\section{Wat vond de visitatiecommissie?}

Ook de Visitatiecommissie Biomedische Wetenschappen en Medische Informatiekunde heeft in 2004 positief geoordeeld over dit systeem van studieleiders, zoals mag blijken uit het volgende citaat: "Het systeem van de studieleiders per hoofdvak verzekert een goede begeleiding en bewaking van de masterprogramma's die door de studenten worden samengesteld. Studieleiders hebben recent de onderwijsprijs van de instelling ontvangen omdat het systeem goed functioneert. Ook de commissie is enthousiast over dit stelsel en de manier waarop daaraan uitstekend invulling wordt gegeven. In het afstudeerplan worden alle onderdelen van het studieprogramma in de masteropleiding 
vastgelegd. Er worden eisen gesteld aan de componenten en omvang daarvan. De student stelt dit afstudeerplan in overleg met de studieleider van het betreffende hoofdvak samen. De studieleider bewaakt de coherentie van het programma. De studieleider heeft eveneens een centrale rol bij het invullen van de wetenschappelijke of praktijkstage en de begeleiding van de eindscriptie."20

\section{Discussie}

\section{Is zelfsturing als concept mogelijk?}

Wij hebben de overtuiging dat het concept van zelfsturing werkt en willen bovenstaande vraag zowel vanuit de theorie als de praktijk beantwoorden.

In zijn oratie concludeert Vermunt ${ }^{21}$ dat studenten het waarderen wanneer ze zelfstandig aan de slag kunnen met taken of opdrachten die zijn ontleend aan de praktijk. In zijn rede bouwt hij voort op het model van procesgerichte instructie dat hij in zijn proefschrift ${ }^{22}$ heeft ontwikkeld. Centraal in dat model staat dat studenten steeds meer invloed krijgen op hun eigen leerprocessen en zich zodoende steeds meer en beter zelf kunnen gaan sturen. De laatste jaren is het concept van procesgerichte instructie bij veel onderwijskundige vernieuwingen gebruikt en heeft het zijn waarde als grondidee bewezen. Wij zijn ervan overtuigd dat het model Vermunt op verschillende plaatsen verder gespecificeerd dient te worden. Daarover later meer.

Een ander model is ontwikkeld door Miflin et al. ${ }^{23} \mathrm{Bij}$ eerdere vernieuwingen waren de onderzoekers aangelopen tegen het probleem dat het concept van zelfsturing verschillend, zelfs conflicterend geïnterpreteerd werd. Ook liepen ze tegen het gegeven aan dat studenten afhankelijker werden van docenten in plaats van zelfstandiger. Om deze negatieve aspecten het hoofd te bieden, ontwikkelden ze een model dat zelfsturing opvat als een cumulatief effect van leren binnen een gehele opleiding. De studenten krijgen hierbij steeds meer verantwoordelijkheid voor hun leren en de sturing door de opleiding neemt geleidelijk af. Het ontstane framework vormt de grondslag voor de blauwdruk van het gehele curriculum en bestaat uit een mix van ondersteuning van het leren door de student en aanmoediging van de student om zijn verantwoordelijkheid hiervoor op te pakken. Hierbij wordt rekening gehouden met de groeiende behoefte van studenten. Het idee erachter is dat de studenten gemotiveerd en in staat zijn hun inspanningen te sturen, omdat ze weten dat ze de vaardigheden ontwikkeld hebben die hen in de tijd in staat stellen duurzaam en doelgericht te leren.

Het voordeel van dit model is dat het aan veel aspecten van het leren aandacht schenkt en zorg draagt voor een geleidelijke opbouw (moeilijker, complexer, meer verantwoordelijkheid e.d.). Ons inziens blijft de rol van de student in het framework onderbelicht.

Taks ${ }^{7}$ onderschrijft onze kritiek op bovenstaande modellen. Haar adviezen voor de praktijk hebben met name betrekking op de nieuwe rollen die studenten en docenten krijgen bij de invoering van het concept van zelfsturing in de onderwijs. Volgens haar vraagt dat om:

- consistentie in het curriculumontwerp en een zorgvuldige opbouw van de verantwoordelijkheden van studenten in het curriculum, waarin de mate van zelfsturing gedurende de opleiding toeneemt en de mate van ondersteuning door docenten afneemt;

- een gezamenlijk gedeelde opvatting binnen een opleiding over wat zelfsturing concreet betekent voor de rollen van studenten en docenten in het onderwijs. 
Geerding, Ophelders en Jansen hebben een model ontwikkeld dat niet alleen de rollen van de docenten en studenten per opleidingsfase uitwerkt, maar dat daarnaast de regulatieve functies per fase gedetailleerd beschrijft en de betrokken docent vraagt op basis van zijn visie op wat zelfsturing voor hem betekent een keuze per jaar of half jaar te maken. Daarnaast hebben ze voorstellen ontwikkeld om naast inhoudelijke opdrachten leertaken te ontwikkelen die studenten daadwerkelijk ondersteunen bij het zich eigen maken van de verschillende leeractiviteiten, zoals zich oriënteren, feedback geven, zich verantwoorden, transfer mogelijk maken en reflecteren. Deze leertaken zijn het eerste en tweede jaar wel te onderscheiden van de inhoudelijke rode draad, maar hebben er daarnaast ook betrekking op. In het vervolg van de studie worden de leerfuncties alleen maar uitgevoerd met de op dat moment te leren inhouden.

Het instituut 'studieleider' aan het UMC Nijmegen functioneert op basis van o.a. de volgende argumenten:

1. De onderwijsvraag van de student is bepalend voor de invulling van de masterfase.

2. De student wordt hiermee medeverantwoordelijk voor de invulling van de studie.

3. Dit stimuleert de betrokkenheid van de student bij de studie.

4. De studieleider functioneert als begeleider en onderwijsmakelaar en draagt al doende zorg voor de coördinatie en afstemming van het individuele onderwijsprogramma van de student met het aanbod. Daarbij bewaakt hij tevens de coherentie van het programma;

5. De rol en de plaats van de studieleiders in de organisatie spelen een belangrijke rol. ${ }^{24}$

\section{Sterkte-zwakte analyse van de onder- zoeken}

Wat de enquête onder de studieleiders betreft, is hun mening uiteraard ten dele gekleurd. Probleem is dat er geen controlegroep is te definiëren. Daarnaast kun je vraagtekens plaatsen bij de objectiviteit van de geformuleerde vragen. Daarentegen gaan we ervan uit dat de visitatiecommissie en de commissie die de universitaire onderwijsprijs heeft toegekend als objectief mogen worden gekwalificeerd. Of je dit ook mag stellen voor studenten blijft de vraag. Echter, als het systeem absoluut niet of slecht zou werken, dan zou dit zeker ook de conclusie van de studenten zijn.

\section{Conclusie}

Onze algemene conclusie is dat de meeste studieleiders conform de bovenvermelde uitgangspunten handelen. In feite zien ze zichzelf als begeleider op afstand. Met het instituut 'studieleider' lijkt een goede balans gevonden te zijn tussen de risico's van zelfsturing zonder kaders en de negatieve effecten van een te directieve opleiding. De studenten moeten het zelf doen: zij zijn op weg naar een academische functie, waarin ze voortdurend zelfstandig allerlei keuzes zullen moeten maken en beslissingen zullen moeten nemen. De docenten, respectievelijk het onderwijsmateriaal, helpen de studenten bij het leren zich zelf te sturen. Dat gebeurt door hen aanwijzingen te geven hoe ze zich dienen te oriënteren op een onderwerp, hoe ze moeten plannen, hoe ze kunnen reflecteren op het geleerde et cetera. Naast aandacht voor deze regulatieve vaardigheden worden ze ook ingewijd in complexe vaardigheden als het schrijven van onderzoeksvoorstellen, het kritisch verwerken van nieuwe informatie en het vergelijken en verklaren van nieuwe bevindingen. Zowel de Nijmeegse als internationale er- 
varing benadrukt dus dat van iemand een zelfsturende student maken heel wat anders is dan iemand alles zelf uit te laten zoeken.

\section{Dankwoord}

De auteurs danken de andere studieleiders voor hun hulp bij het schrijven van dit artikel: dr. P. van der Kraan, dr. J. Kooloos, prof. dr. G.J. van der Wilt, dr. P. Scheepers en prof. dr. L. Kiemeney.

\section{Literatuur}

1. Schol S, Cort P de, Stubbe C, Vantroyen D, Vervaeck N. Professionalisering van praktijkopleiders via persoonlijke leerplanbegeleiding: evaluatie van een vernieuwd project. Tijdschrift voor Medisch Onderwijs 2003;22(3):115-23.

2. Willems J, Ehlen C. Visie op en implementatie van vraaggestuurd competentiegericht maatwerkonderwijs. TH\&MA: tijdschrift voor hoger onderwijs en management 2005;12(1):38-44.

3. Bolhuis S. Towards process-oriented teaching for self-directed lifelong learning: a multidimensional perspective. Learning and Instruction 2003;13(3):327-47.

4. Greveson GC, Spencer JA. Self-directed learning the importance of concepts and contexts. Med Educ 2005;39:348-9.

5. Dornan T, Hadfield J, Brown M, Boshuizen H, Scherpbier A. How medical students learn in a self-directed way in the clinical environment? Design-based research. Med Educ 2005;39:356-64.

6. Eva KW. On the generality of specificity. Med Educ 2003;37:587-8.

7. Taks MMMA. Zelfsturing in leerpraktijken. Een curriculumonderzoek naar nieuwe rollen van studenten en docenten in de lerarenopleiding [dissertation]. Enschede: Universiteit Twente; 2003.

8. Witteman H. Oude didactiek past niet in nieuwe onderwijsvisies. TH\&MA: tijdschrift voor hoger onderwijs en management 2001;8(1):17-25.

9. Stijnen S, Dieleman A. Lerende leraren als regisseur van hun eigen leerproces? Develop: kwartaaltijdschrift over human resources development 2005;1(2):32-41.

10. Vermunt JD, Verloop N. Conguence and friction between learning and teaching. Learning and Instruction 1999;9:257-80.

11. Vermetten YJ, Lodewijks HG, Vermunt JD. Consistency and variability of learning strategies: a phenomenografic analysis. Higher Educ 1999;31:25-50.
12. Hoban JD, Lawson SR, Mazmanian PE, Best AM, Seibel HR. The Self-Directed Learning Readiness Scale: a factor analysis study. Med Educ 2005;39:370-9.

13. Baveye P. Refocusing the self-directed learning debate. Fam Med 2003;35(6):445-6.

14. Holdrinet RSG, Bulte JA. Realisering van een vernieuwd Nijmeegs curriculum Geneeskunde. Nijmegen: Universitair Medisch Centrum St Radboud, Katholieke Universiteit Nijmegen; 2002.

15. Smeijsters H, Sporken S, editors. Van taak tot competentie. 'Leren leren' voor het hoger beroepsonderwijs. Houten/Antwerpen: Bohn Stafleu van Loghum; 2004.

16. Schelfhout W. Kritische beschouwingen bij het constructivisme. Naar een evenwichtsmodel voor het verwerven van kennis en competenties. TVHO 2002;20(2):94-124.

17. Griffioen A. Gewapend beton. Op zoek naar een stevig fundament voor competentiegericht onderwijs [scriptie] Utrecht: CLU, Universiteit Utrecht; 2002.

18. Cluitmans J, Klarus R. Competentiebeoordeling: een pleidooi voor congruentie. TVHO 2005;23(4): 221-38.

19. Migchelbrink F. Praktijkgericht onderzoek in zorg en welzijn. Amsterdam: Uitgeverij SWP; 2002.

20. QANU. Onderwijsvisitatie biomedische wetenschappen en medische informatiekunde. Utrecht; december 2004.

21. Vermunt J. Studeren voor nieuwe geleerden: over de kwaliteit van het leren. Rede in verkorte vorm uitgesproken bij de aanvaarding van het ambt van hoogleraar Onderwijskunde aan de Faculteit der Gezondheidswetenschappen van de Universiteit Maastricht op vrijdag 17 november 2000.

22. Vermunt JDHM. Leerstijlen en sturen van leerprocessen in het hoger onderwijs. Naar procesgerichte instructie en zelfstandig denken. Amsterdam/Lisse: Swets \& Zeitlinger; 1992.

23. Miflin BM, Campbell CB, Price DA. A conceptual framework to guide the development of self-directed, lifelong learning in problem-based medical curricula. Med Educ 2000;34:299-306.

24. Blom CWPM, et al. Universitaire onderwijsprijs 2003. Nijmegen: Katholieke Universiteit Nijmegen; juli 2003.

De auteurs:

Dr. Rob P. Bos is toxicoloog en verbonden aan de afdeling Farmacologie-Toxicologie van het UMC St Radboud te Nijmegen.

Drs. Gé A.M. Ophelders is als senior adviseur verbonden aan het IOWO, Adviseurs voor onderwijs, beleid en organisatie, Radboud Universiteit Nijmegen. 
Correspondentieadres:

Dr. Rob P. Bos, UMC St Radboud, Farmacologie-Toxicologie, M236, Postbus 9101, 6500 HB Nijmegen, tel.: 024-3614203,r.bos@pharmtox.umcn.nl.

Drs. Gé A.M. Ophelders, Radboud Universiteit Nijmegen, IOWO, Mercator I, Postbus 6540, 6503 GA Nijmegen, tel.: 024-3615582,g.ophelders@iowo.ru.nl.
Belangenconflict: geen gemeld.

Financiële ondersteuning: geen gemeld.

\section{Summary}

After the biomedical sciences curriculum at Nijmegen Radboud University had been restructured by dividing it into a three-year bachelor phase and a two-year master phase, students were faced with more choices during the new master phase. To support the students, six coaches were appointed. This article describes the functioning of the coaches within the new educational and organisational context against the background of the literature on students 'self-directed learning, self-reflection and responsibility for their own learning. The desired qualities of coaches are also addressed. The effectiveness of the work of the coaches was explored in semi-structured one-to-one interviews and focus group interviews with the coaches. Additional information was obtained from the report of the national education audit. In general, it is concluded that the coaching is effective and that a good balance is struck between guidance and self-directedness of students. (Bos RP, Ophelders GAM. Coaching and self-directed learning during the master phase of the Nijmgen biomedical sciences curriculum. Dutch Journal of Medical Education 2006;25(5):208-217.) 